\title{
SCIENTIFIC COMMUNICATION
}

\section{PROCESO DE INFECCIÓN DE ANTRACNOSIS POR Colletotrichum truncatum EN PAPAYA MARADOL ${ }^{1}$}

\author{
INDIRA ROJO-BÁEZ ${ }^{2}$, RAYMUNDO SAÚL GARCÍA-ESTRADA ${ }^{3}$, \\ ADRIANA J. SAÑUDO-BARAJAS ${ }^{4}$, JOSEFINA LEÓN-FÉLIX ${ }^{5}$, RAÚL ALLENDE-MOLAR ${ }^{6}$
}

RESUMEN Colletotrichum truncatum es un hongo patógeno causante de antracnosis en fruto de papaya (Carica papaya L.) y responsable de pérdidas postcosecha. El objetivo de este trabajo fue inducir el proceso de infección de C. truncatum en frutos de papaya var. Maradol bajo condiciones controladas y decribir el progreso de la enfermedad mediante herramientas histopatológicas y microscopía óptica para elucidar el ciclo de vida del patógeno. La penetración directa de la cutícula por medio de apresorios ocurrió alrededor de las 30 h después de inoculación (hdi); las hifas intramurales crecieron en las paredes celulares de células epidérmicas a las 30-48 hdi; la colonización necrotrófica inició a las 72 hdi; hifas intracelulares crecieron dentro de celulas de parénquima causando una extensiva degradación celular lo cual se asocia a la producción de lesiones típicas de antracnosis. El rompimiendo de la cutícula del hospedero ocurrió entre las 96-148 hdi. El ciclo de vida del patógeno se completó a las 96 hdi con la formación de acérvulos. Las observaciones microscópicas en frutos de papaya revelaron que $C$. truncatum es un patógeno intramural subcuticular.

Palabras clave: Carica papaya L., patogénesis, patógeno intramural.

\section{INFECTION PROCESS OF ANTHRACNOSE BY Colletotrichum truncatum ON PAPAYA MARADOL}

\begin{abstract}
Colletotrichum truncatum is a pathogenic fungus causing anthracnose in papaya fruit (Carica papaya L.) and responsible for losses on postharvest. The purpose of this work was to induce the infection process of C. truncatum on fruit of papaya cv. Maradol under controlled conditions and to describe the disease progress by histopathological and light microscopy tools in order to elucidate the pathogen life cycle. Direct cuticle penetration by appresoria occurred around $30 \mathrm{~h}$ after inoculation (hai); the intramural hyphae grew on the epidermic cell wall layer at 30-48 hai;necrotrophic colonization started at 72 hai; intracellular hyphae grew into parenchymal cells causing extensive cell wall degradation in association to water-soaked lesions production. The time for the host cuticle breakdown occurred between 96-148 hai. The pathogen life cycle was completed at 96 hai with acervuli formation. Microscopic observations on papaya fruits revealed that C. truncatum is a subcuticular intramural pathogen.
\end{abstract}

Index terms: Carica papaya, pathogenesis, intramural pathogen.

${ }^{1}$ (Paper 246-15). Received October 28, 2015. Accepted July 19,2016.

${ }^{2}$ M.C. Centro de Investigación en Alimentación y Desarrollo, A. C. Carretera Culiacán a El Dorado, km 5.5. Campo el Diez, C. P. 80110, Culiacán, Sinaloa, México. Tel. (+52) 6677605536. E-mail:indira.rojo@estudiantes.ciad.mx

${ }^{3}$ Dr. Investigador titular. Departamento de Fitopatología. CIAD Culiacán. E-mail: rsgarcia@ciad.mx

${ }^{4}$ Dra. Investigador titular. Departamento de Bioquímica Vegetal. CIAD Culiacán. E-mail: ljosefina@ciad.mx

${ }^{5}$ Dra. Investigador titular. Departamento de Biología Molecular. CIAD Culiacán. E-mail: adriana@ciad.mx

${ }^{6}$ Dr. Investigador titular. Departamento de Fitopatología. CIAD Culiacán. E-mail: rallende@ciad.mx. 
Antracnosis, una de las principales enfermedades que afectan a papaya (Carica papaya L.), se encuentra distribuida en áreas tropicales y subtropicales a nivel mundial afectando frutos en pre- y poscosecha. En México, las pérdidas reportadas superan el $50 \%$. Además, la antracnosis en papaya se asociaba solamente con el hongo Colletotrichum gloeosporioides cuya infección causa lesiones húmedas, hundidas y con masas de conidios de color naranja (TORRES-CALZADA et al., 2013); sin embargo, en 2008 se reportó adicionalmente a $C$. truncatum (Schwein) Andrus \& W.D. Moore (antes C. capsici) (MAHMODI et al., 2014) (TAPIATUSSELL et al., 2008) cuya infección causa lesiones de color marrón a negro, con masas de esporas de color gris y abundantes acérvulos dispuestos concéntricamente (TAPIA-TUSSELL et al., 2008); además, presenta una incidencia de hasta $40 \%$ (TORRES-CALZADA et al., 2013). Si bien se reportó a $C$. truncatum como agente causal de antracnosis en papaya, son escasos los estudios enfocados al proceso de patogénesis en este hospedero. Un aspecto importante del proceso de patogénesis es la estrategia de infección empleada por el patógeno (PERFECT et al., 1999). De acuerdo al hospedero, C. truncatum utiliza estrategias de infección diferentes, ya que se comporta como patógeno hemibiotrófico intracelular en chícharo, haba y lenteja (O'CONNELL et al., 1993; LATUNDEDADA; LUCAS, 2007; ARMSTRONG-CHO et al., 2012; BHADAURIA et al., 2013) o como patógeno intramural subcuticular en chile (AUYONG et al., 2012; RANATHUNGE et al., 2012). En papaya, se desconoce la estrategia de infección que emplea $C$. truncatum para causar antracnosis en frutos. El objetivo de este estudio fue describir, mediante técnicas histológicas, la estrategia de infección que utiliza C. truncatum en fruto de papaya Maradol. La cepa CCM de C. truncatum, previamente caracterizada molecularmente (KF147902), proveniente de un fruto de papaya cv. Maradol con antracnosis se utilizó en los ensayos de patogenicidad. Veinte frutos sanos de papaya en madurez de consumo se lavaron con agua corriente, se secaron, se desinfectaron con una solución de hipoclorito de sodio al $1 \%$ y con etanol al $70 \%$, se lavaron con agua destilada y se secaron a temperatura ambiente; posteriormente, quince frutos se inocularon artificialmente, en tres puntos de la superficie $\left(1 \mathrm{~cm}^{2}\right)$ sin causar heridas con $10 \mu \mathrm{L}$ de una suspensión de esporas $\left(1 \times 10^{6}\right.$ esporas $\left./ \mathrm{mL}\right)$, previamente colectadas de un cultivo monospórico de $C$. truncatum de siete días de crecimiento en PDA. A cinco frutos testigo (un fruto por día) solo se les colocó $10 \mu \mathrm{L}$ de agua destilada estéril. Se tomaron secciones de tejido de las áreas inoculadas a las 2, 4 , $6,9,12,18,20,24,30,48,60,72,96,120$ y $148 \mathrm{~h}$ después de inoculación (hdi). Todos los frutos se colocaron en cámara húmeda a $25^{\circ} \mathrm{C} \pm 2{ }^{\circ} \mathrm{C}$ durante seis días (MORAES et al., 2013). A las 148 hdi, se midió el diámetro de la lesión en frutos usando un calibrador (Vernier, México). Se analizaron porciones de tejido de $5 \mathrm{~mm}$ de las áreas inoculadas; las cuales se colocaron en casetes de plástico, se etiquetaron y se sumergieron en solución fijadora FAA (Formaldehido-ácido acético-alcohol) donde permanecieron al menos durante $24 \mathrm{~h}$. Posteriormente, los tejidos se deshidrataron con concentraciones crecientes de alcohol etílico (50, 70, 80, 96 y $100 \%)$ y se infiltraron en parafina, mediante la transferencia en alcohol absoluto-xileno (v/v), en xileno (dos veces) y en parafina Leica (dos veces). Los tejidos permanecieron en las soluciones durante $3 \mathrm{~h} \mathrm{y}$ finalmente, se agitaron dos veces en un procesador de tejidos centrífugo (Thermo Scientific, STP 120, GER) (CASARRUBIAS-CARRILLO et al., 2002). En un centro de inclusión (Thermo Scientific, HistoStar, UK), los tejidos se colocaron en moldes metálicos con parafina fundida, se orientaron vertical y horizontalmente, se les colocó un casete de plástico, se agregó parafina fundida y se dejaron enfriar; posteriormente, los tejidos se colocaron en un micrótomo semiautomático (Thermo Scientific, Microm HM340E, GER) y se obtuvieron cortes longitudinales y transversales de $6 \mu \mathrm{m}$ de grosor. Los cortes se colocaron en portaobjetos con adhesivo Haupt, colocándolos previamente en un baño de flotación (Fisher Scientific, model 134, USA) con agua caliente $\left(50{ }^{\circ} \mathrm{C}\right)$, se les eliminó el exceso de agua y se secaron a temperatura ambiente durante 24 h. Brevemente, se eliminó la parafina de los tejidos mediante tres lavados de 3 min con xileno y después se deshidrataron con concentraciones decrecientes de etanol $(100,96,70$ y $50 \%)$ durante 3 min cada uno. Se realizó la tinción con safranina al $1 \%$ en alcohol etílico al $50 \%$, durante $2 \mathrm{~h}$. Posteriormente, los cortes se deshidrataron en una serie gradual de etanol (50, 70 y $96 \%$ ) durante 3 min cada uno. Se realizó la tinción con verde-rápido al $1 \%$ en etanol al $96 \%$, durante 30 s. Posteriormente, se realizó un lavado con alcohol absoluto y tres lavados con xileno durante $3 \mathrm{~min}$, respectivamente; finalmente, a los portaobjetos se les agregó resina Entellan y se secaron durante $24 \mathrm{~h}$ (RODRÍGUEZ-LÓPEZ et al., 2013). Las laminillas se observaron en un microscopio óptico marca Carl Zeiss Axiostar Imager A2 con cámara integrada. Los apresorios se midieron con el software ZEN 2012 (blue edition). La germinación de los conidios de C. truncatum en fruto de papaya, 
inició a partir de las 20 hdi. Los tubos germinativos emergieron a partir de los conidios de manera polar y lateral. A las $30 \mathrm{hdi}$, a partir del tubo germinativo se formaron apresorios melanizados, de coloración café oscura, de forma globosa a irregular con medidas promedio de $7.42 \times 4.89 \mu \mathrm{m}$ (Figura 1B). Las especies de Colletotrichum forman apresorios melanizados para facilitar la adhesión y la penetración, por medio de acción mecánica y lisis enzimática (KLEEMANN et al., 2012). Debido a la formación de apresorios, la penetración fue de manera directa. En los apresorios se observó un punto carente de melanina lo que sugiere un poro donde ocurre segregación enzimática necesaria durante la penetración (RANATHUNGE et al., 2012). $C$. truncatum segrega cutinasa para romper la cutícula del hospedero; por ejemplo, en chile la cutinasa es esencial para causar la ruptura de la cutícula (AUYONG et al., 2015). De acuerdo con Dickman et al. (1982), C. gloeosporioides produce cutinasa extracelular, como estrategia de penetración de la cutícula en frutos de papaya en madurez fisiológica y comercial. Además, se observó una coloración rojiza en las células epidérmicas en contacto con los apresorios (Figura 1B). De acuerdo con RodríguezLópez et al. (2013) el desarrollo de C. gloeosporioides se relacionó con una coloración roja en células epidérmicas y células de parénquima del exocarpio de aguacate producto de la metabolización de polifenoles. La producción de polifenoles se relaciona con la restricción del crecimiento fúngico en el sitio de infección (VARGAS et al., 2012). Se observaron hifas intramurales en las paredes de las células epidérmicas del hospedero entre las 30 y 48 hdi. Por otro lado, en este estudio no fue posible observar hifas debajo de la cutícula como en el estudio de Diéguez-Uribeondo et al. (2005); no obstante, se observaron hifas intramurales en las paredes de las células epidérmicas del hospedero (Figura 1C), por lo que se puede inferir que la hifa de infección atravesó la capa subcuticular a lo largo de la pared celular de la epidermis (RANATHUNGE et al., 2012). De acuerdo con Pring et al. (1995), las hifas intramurales crecieron en las paredes celulares de las células epidérmicas. Por otra parte, las hifas intracelulares se observaron en células de parénquima a las 72 hdi, las hifas de infección atravesaron las paredes celulares del hospedero (Figura 1D). En esta etapa el patógeno obtiene nutrientes del contenido celular del hospedero por lo que la infección se asocia principalmente con la producción de enzimas líticas tales como proteasas y enzimas carbohidrato-activas que degradan los polisacáridos de las paredes celulares (O’CONNELL et al., 2012). A las 96 hdi se observó una extensa colonización de células epidérmicas y de parénquima sin daño en la cutícula ya que se observó crecimiento de hifas subcuticulares (Figura 1E), las cuales podrían estar involucradas en la formación de los acérvulos. De acuerdo con Moraes et al. (2013), durante el estado necrótrofo, C. gloeosporioides produce hifas intracelulares que colonizan células epidérmicas y de parénquima en su interacción con guayaba. La formación de acérvulos inició a partir de las 96 hdi y hasta las 148 hdi. Los acérvulos, emergieron de la superficie del hospedero al romper la cutícula (Figura 1F). La presencia de múltiples acérvulos se asoció con zonas hundidas de coloración oscuro en la superficie del fruto, cuyo diámetro fue de $4.2 \mathrm{~cm}$, en contraste con el fruto testigo el cual no presentó síntomas de enfermedad (Figura 1A). El daño celular y la producción de acérvulos se asociaron a la aparición de los síntomas de enfermedad los cuales iniciaron a las 72 hdi, lo cual contrasta con lo reportado por Casarrubias-Carrillo (2002), quienes señalan que los síntomas de enfermedad en fruto de papaya en madurez comercial ocasionados por $C$. gloeosporioides iniciaron a las 90 hdi. El hecho de que $C$. truncatum ocasionó síntomas de antracnosis al tercer día de infección puede deberse a la formación de apresorios, lo que le permitió penetrar de manera directa la cutícula intacta del fruto de papaya y así iniciar la infección; a diferencia de $C$. gloeosporioides el cual no formó apresorios en su interacción con papaya lo que ocasionó la aparición tardía de los síntomas de enfermedad. En conclusión, en fruto de papaya, C. truncatum utilizó la estrategia de infección intramural subcuticular, causó síntomas de antracnosis a las $72 \mathrm{~h}$, y produjo acérvulos desde las 96 h después de inoculación con lo que completó su ciclo de vida. C. truncatum se comporta como patógeno intramural subcuticular en su interacción con el fruto de papaya; estos resultados contribuyen a entender el proceso de infección en el ciclo de la enfermedad causada por C. truncatum en frutos de papaya y serán útiles para plantear nuevas estrategias para el control de la enfermedad. Se agradece al proyecto 2011-163213 "El manejo integral del cultivo de papaya en México, un acercamiento innovador" financiado por SAGARPA, al CONACyT por el financiamiento a los estudios de I. Rojo-Báez y a la Dra. Apolinar Santamaría Miranda del CIIDIRIPN Sinaloa por su apoyo para realizar el análisis histopatológico en su laboratorio. 


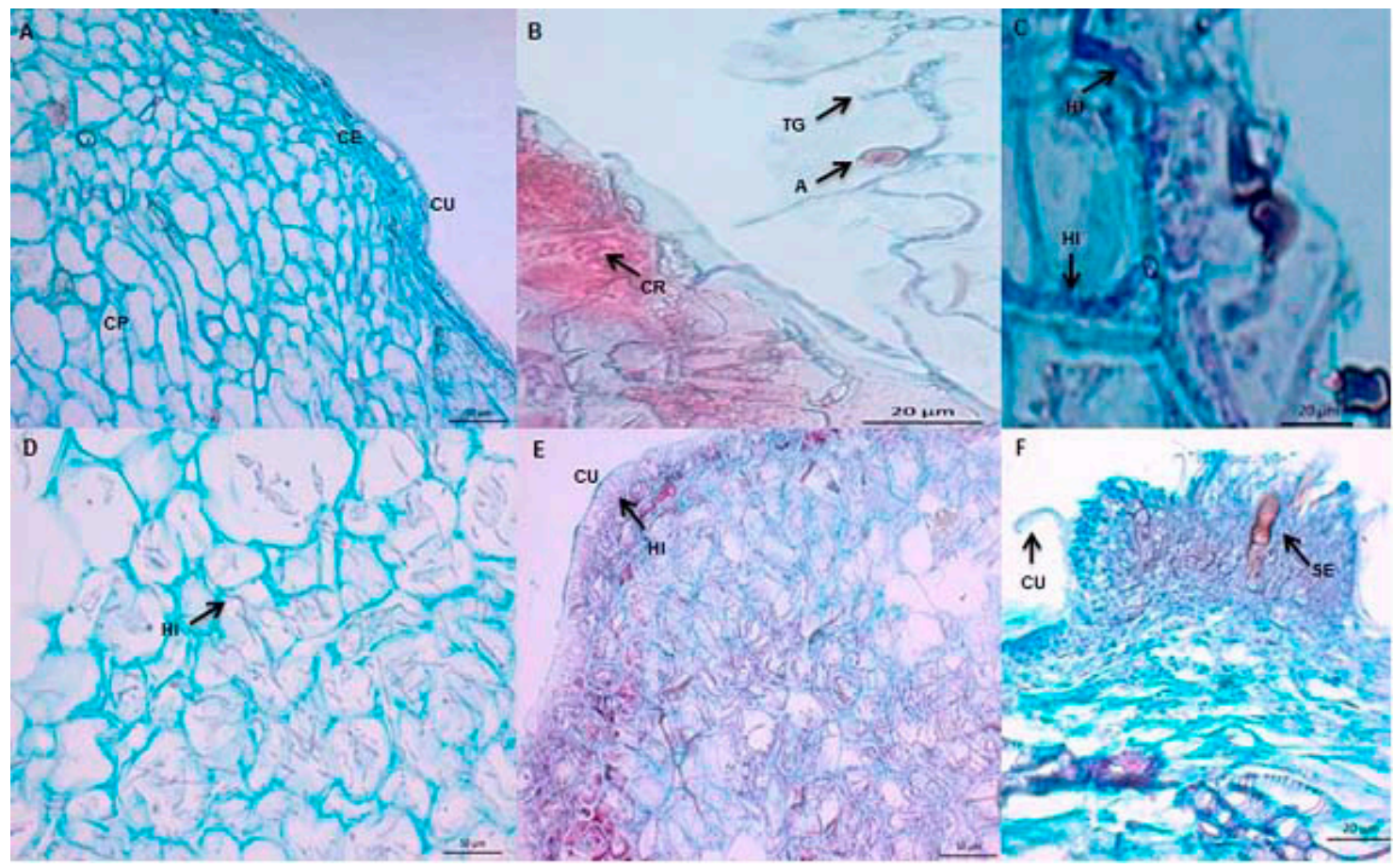

FIGURA 1-Fotomicrografías del proceso de infección de C. truncatum en frutos de papaya Maradol en madurez comercial. A) Corte longitudinal de fruto sano de papaya $(\mathrm{CU}=$ cutícula; $\mathrm{CE}=$ células epidérmicas; $\mathrm{CP}=$ células de parénquima; Barra $=50 \mu \mathrm{m})$. B) Corte longitudinal de fruto infectado a las $30 \mathrm{~h}$ después de inoculación (hdi), se observa conidio con tubo germinativo y apresorio melanizado, coloración rojiza en células epidérmicas $(A=$ apresorios melanizados; $\mathrm{TG}=$ tubos germinativos; $\mathrm{CR}=$ coloración rojiza; Barra $=20 \mu \mathrm{m}) . \mathrm{C}$ ) Corte longitudinal de fruto infectado por $C$. truncatum a las $30 \mathrm{hdi}$, hifas intramurales en células epidérmicas $(\mathrm{HI}=$ hifas intramurales; Barra $=20 \mu \mathrm{m})$. D) Corte longitudinal de fruto infectado a las $72 \mathrm{hdi}$, hifas intracelulares en células de parénquima $(\mathrm{HI}=$ hifas intracelulares; Barra $=50 \mu \mathrm{m})$. E) Corte longitudinal de fruto infectado a las 96 hdi, hifas intracelulares debajo de la cutícula $(\mathrm{CU}=$ cutícula; Barra $=50 \mu \mathrm{m}$ ). F) Corte trasversal de fruto infectado a las $148 \mathrm{hdi}$, acérvulo con setas emergiendo de epidermis $(\mathrm{CU}=$ cutícula; $\mathrm{SE}=$ setas; $\mathrm{Barra}=20 \mu \mathrm{m})$.

\section{REFERENCIAS}

ARMSTRONG-CHO, C.; WANG, J.; WEI, Y.; BANIZZA, S. The infection process of two pathogenic races of Colletotrichum truncatum on lentil. Canadian Journal Plant Pathology, Alberta, v.34, n.1, p.58-67, 2012.

AUYONG, A.S.M.; FORD, R.; TAYLOR, P.W.J. Genetic transformation of Colletotrichum truncatum associated with anthracnose disease of chili by random insertional mutagenesis. Journal of Basic Microbiology, Weinheim, v.52, n.4, AUYONG, A.S.M.; FORD, R.; TAYLOR, P.W.J. The role of cutinase and its impact on pathogenicity of Colletotrichum truncatum. Journal Plant Pathology \& Microbiology, Geneva, v.6, n.3, p.259, 2015. Disponivel em: $<\underline{\text { http://dx.doi.org/10.4172/2157- }}$ 7471.1000259>. Acesso em: 5 jul. 2016.

BHADAURIA, V.; BANNIZA, S.; VANDENBERG, A.; SELVARAJ, G.; WEI, Y. Overexpression of a novel biotrophy-specific Colletotrichum truncatum effector, CtNUDIX, in hemibiotrophic fungal phytopathogens causes incompatibility with their host plants. Eukaryotic Cell, Washington, v.12, n.1, p.2-11, 2013. p.372-382, 2012. 
CASARRUBIAS-CARRILLO, U.; CÁRDENASSORIANO, E.; NIETO-ÁNGEL, D.; GUTIÉRREZALONSO, G. Histopatología de frutos de papaya (Carica papaya L.) infectados por Colletotrichum gloeosporioides Penz. Revista Mexicana de Fitopatología, Ciudad Obregón, v.20, n.1, p.88-93, 2002.

DICKMAN, M.B.; PATIL, S.S.; KOLATTUKUDY, P.E. Purification, characterization and role in infection of an extracelular cutinolytic enzyme from Colletotrichum gloeosporioides Penz. on Carica papaya L. Physiological Plant Pathology, Michigan, v.20, n.3, p.333-347, 1982.

DIÉGUEZ-URIBEONDO, J.; FÖRSTER, H.; SOTOESTRADA, A.; ADASKAVEG, J.E. Subcuticularintracellular hemibiotrophic and intercellular necrotrophic development of Colletotrichum acutatum on almond. Phytopathology, St. Paul, v.95, n. 7, p.751-758, 2005.

KLEEMANN, J.; RINCON-RIVERA, L.J.; TAKAHARA, H.; NEUMANN, U.; THEMAAT, E.V.L.V.; DOES, C.V.D.; ET AL. Sequential delivery of host-induced virulence effectors by appressoria and intracellular hyphae of the phytopathogen Colletotrichum higginsianum. Plos Pathogens, San Francisco, v.8, n.4, p.1-15, 2012.

LATUNDE-DADA, A.O.; LUCAS, J.A. Localized hemibiotrophy in Colletotrichum: cytological and molecular taxonomic similarities among $C$. destructivum, C. linicola and $C$. truncatum. Plant Pathology, Chichester, v.56, n.3, p.437-447, 2007.

MAHMODI, F.; KADIR, J.B.; PUTEH, A.; POURDAD, S.S.; NASEHI, A.; SOLEIMANI, N. Genetic diversity and differentiation of Colletotrichum spp. isolates associated with leguminosae using multigene loci, RAPD and ISSR. Plant Pathology Journal, Suwon, v.30, n.1, p.10-24, 2014.

MORAES, G.S.R.; TANAKA O.F.A.; MASSOLA J.N.S. Histopathology of Colletotrichum gloeosporioides on guava fruits (Psidium guajava L.). Revista Brasileira de Fruticultura, Jaboticabal, v.35, n.2, p.657-664, 2013.

O'CONNELL, R.J.; URONU, A.B.; WAKSMAN, G.; NASH, C.; KEON, J.P.R.; BAILEY, J.A. Hemibiotrophic infection of Pisum sativum by Colletotrichum truncatum. Plant Pathology, London, v.42, n.5, p.774-783, 1993.
O'CONNELL, R.J.; THON, M.R.; HACQUARD, S.; AMYOTTE, S.G.; KLEEMANN, J.; TORRES, M.F; ET AL. Lifestyle transitions in plant pathogenic Colletotrichum fungi deciphered by genome and transcriptome analyses. Nature Genetics, New York, v.44, n.9, p.1060-1067, 2012.

PERFECT, S.E.; HUGHES, H.B.; O'CONNELL, R.J.; GREEN, J.R. Colletotrichum: A model genus for studies on pathology and fungal-plant interactions. Fungal Genetics and Biology, Orlando, v.27, n.2, p.186-198, 1999.

PRING, R.J.; NASH, C.; ZAKARIA, M.; BAILEY, J.A. Infection process and host range of Colletotrichum capsici. Physiological and Molecular Plant Pathology, London, v.46, p.137$152,1995$.

RANATHUNGE, N.P.; MONGKOLPORN, O.; FORD, R.; TAYLOR, P.W.J. Colletotrichum truncatum pathosystem on Capsicum spp: infection, colonization and defense mechanisms. Australasian Plant Pathology, Collingwood, v.41, p.463-473, 2012.

RODRÍGUEZ-LÓPEZ, E.S.; CÁRDENASSORIANO, E.; HERNÁNDEZ-DELGADO, S.; GUTIÉRREZ-DIEZ, A.; MAYEK-PÉREZ, N. Análisis de la infección de Colletotrichum gloeosporioides (Penz.) Penz. \& Sacc. de frutos de aguacatero. Revista Brasileira de Fruticultura, Jaboticabal, v.35, n.3, p.898-905, 2013.

TAPIA-TUSSELL, R.; QUIJANO-RAMAYO, A.; CORTES-VELÁZQUEZ, A.; LAPPE, P.; LARQUE-SAAVEDRA, A.; PEREZ-BRITO D. PCR-based detection and characterization of the fungal pathogens Colletotrichum gloeosporioides and Colletotrichum capsici causing anthracnose in papaya (Carica papaya L.) in the Yucatán peninsula. Molecular Biotechnology, Totowa, v.40, n.3, p.293298, 2008.

TORRES-CALZADA, C.; TAPIA-TUSSELL, R.; HIGUERA-CIAPARA, I.; PÉREZ-BRITO, D. Morphological, pathological and genetic diversity of Colletotrichum species responsible for anthracnose in papaya (Carica papaya L). European Journal of Plant Pathology, Sochi, v.135, n.1, p.67-79, 2013.

VARGAS, W.A.; SANZ, M.J.M.; RECH, G.E.; RIVERA, L.P.; BENITO, E.P.; DÍAZ-MÍNGUEZ, J.M.; ET AL. Plant defense mechanisms are activated during biotrophic and necrotrophic development of Colletotrichum graminicola in maize. Plant Physiology, Rockville, v.158, n.3, p.1342-1358, 2012. 